\title{
REFLEXIONES SOBRE LA PRÁCTICA DEL REGALISMO: GRACIA REGIA Y ALTA CARRERA ECLESIÁSTICA DURANTE EL REINADO DE CARLOS III (1759-1788)*
}

POR

\author{
ANDONI ARTOLA RENEDO \\ Universidad del País Vasco
}

\begin{abstract}
RESUMEN: Desde el ascenso de los Borbones al trono español, se implantó una política de control estatal de la Iglesia que tiene sus principales hitos de victoria en la firma del Concordato de 1753 y la expulsión de los jesuitas en 1767. En este contexto, la carrera eclesiástica cambió sus caracteres de forma notable, pivotando en torno a la gracia real, que se convirtió en el elemento clave de integración o exclusión política del clero secular. Este artículo analiza, bajo este marco, los elementos políticos que influían en la carrera eclesiástica durante el reinado de Carlos III.
\end{abstract}

PALABRAS CLAVES: Monique, Patronato Real, Regalismo, Clero secular, Carlos III

REFLECTIONS ON THE PRACTICE OF REGALISM: THE POLITICAL FRAMEWORK OF THE UPPER ECCLESIASTICAL CAREER UNDER CHALES III (1759-1789)

ABSTRACT: From the ascent of the Bourbons to the Spanish throne, a policy of state control of the Church was implanted, whose main

*Proyecto de investigación del Ministerio de Ciencia e Innovación HAR2010-21325-C05-02: "Las élites de la modernidad: Familias, redes y cambio social, de las comunidades tradicionales a la revolución liberal, 16001850". 
landmarks of victory were to found in the signature of the Concordat of 1753 and the expulsion of the Jesuits in 1767. With this background, the ecclesiastical career changed its characters in remarkable form, pivoting around the royal grace, which became the key element of integration or political exclusion of the secular clergy. Within this frame, this paper analyzes the political elements that influenced the ecclesiastical career during the reign of Charles III of Spain.

KEY WORDS: Monarchy, Royal Patronage, Regalism, Secular clergy, Charles III

\section{Recibido/Received: $\quad$ 26-08-2009 Aceptado/Accepted: $\quad 31-07-2013$}

Es cosa generalmente aceptada que el siglo XVIII vio un paulatino acrecentamiento de la capacidad de actuación del Estado en diversos campos. En este proceso, la pretensión de los sucesivos monarcas y sus ministros de hacerse con todos los resortes del poder eclesiástico que pudieran ayudar a llevar adelante su acción gubernamental fue un elemento clave. El Concordato de 1753, tras el cual el rey presentaba la inmensa mayoría de los beneficios eclesiásticos, constituiría, en este sentido, el cenit de un dilatado proceso de recuperación (o incorporación, según la posición desde la que se considere) de regalías o prerrogativas en materia eclesiástica por parte de la Corona que, por una parte, era fruto del reforzamiento del Estado y que, por la otra, redundaría en una mayor eficacia de gobierno al aumentar los recursos disponibles para el ejercicio del poder. ${ }^{1}$

La confluencia del regalismo de raigambre hispánica con la introducción de un fuerte influjo galicano, arribado con la nueva dinastía, traería cambios importantes en la manera de entender la relación de la Corona tanto con el clero español, como con la corte romana. ${ }^{2}$ Los equipos ministeriales de los Borbones se sirvieron crecientemente de la

${ }^{1}$ Siguen siendo de consulta obligada Olaechea, R. 1965. Las relaciones hispanorromanas en la segunda mitad del siglo XVIII. La agencia de preces. Zaragoza, y Hermann, Ch. 1988. L'Église d'Espagne sous le patronage royal. Essai d'ecclésiologie politique. Madrid: Casa de Velázquez. Ver también Pujol Aguado, J. A. 1995. "El clero secular al servicio del Estado. Intento estatal de control de la Iglesia durante la Guerra de Sucesión". Revista de Historia Moderna, 13-14: 73-93.

${ }^{2}$ Mestre Sanchís, A. 2002. "Nueva dinastía e Iglesia nacional", en P. Fernández Albaladejo (ed.), Dinastía y memoria de España en el siglo XVIII: 548-567. Madrid: Marcial Pons / Casa de Velázquez. Paquette, Gabriel G. 2008. Enlightenment, Reform and Governance in Spain and its Empire, 17591808): 56-92. Basingtoke/Nueva York: Palgrave Macmillan. 
estructura eclesiástica para utilizar a su favor unos canales privilegiados de información y transmisión de valores. Se intentaba trasladar así a su ámbito de actuación el prestigio del que el clero gozaba entre amplias capas de la población, y del cual el Estado tendía a apropiarse por la lógica propia de su evolución ${ }^{3}$.

La imbricación entre proyecto de reforma eclesiástica y el desarrollo del Estado es de una evidencia aplastante en toda Europa. Ambas dimensiones se relacionan. La subrogación de los derechos de la Santa Sede tras el Concordato servía tanto a las necesidades materiales de la Corona como al proyecto político que sus ministros proponían. El aparato de gobierno de la monarquía, en constante crecimiento y consolidación, necesitaba de un saneamiento ininterrumpido de su Hacienda. La apropiación de la enorme cantidad de caudales que constantemente afluían hacia Roma como consecuencia de la expedición de bulas por nombramientos, dispensas, etc. fue, sin duda, uno de los principales intereses de la Corona en el arduo proceso de negociación con la Santa Sede. En otro plano está la cuestión del dirigismo de la influencia ideológica del clero. Asegurarse una clerecía fiel y adicta era un objetivo prioritario del Estado. La presentación de la gran mayoría de los beneficios eclesiásticos era una forma de intervención necesaria para convertir a la Iglesia en sus reinos en un instrumento que facilitara llevar a cabo la política reformista. Sin modificar (en principio) lo más mínimo las estructuras eclesiásticas, se trataba de convertir al clero, principal productor discursivo de la época, en instrumentum regni que apoyara y difundiera las iniciativas que partían desde la corte y los círculos reformistas. ${ }^{4}$

La legitimación del Estado era, de hecho, uno de los roles "estructurales" que se asignaba a un clero secular presente en todos los

${ }^{3}$ Cortés Peña, A. L./López Muñoz, M. A. 1996. "Las visitas "ad limina" y las visitas pastorales como instrumento de control (la diócesis de Granada en la segunda mitad del siglo XVIII)", en J. L. Castellano, (ed.): Sociedad, administración y poder en la España del Antiguo Régimen: 288-289. Granada: Universidad de Granada/Diputación Provincial de Granada.

${ }^{4}$ Olaechea, R. 1981. "Política eclesiástica del gobierno de Fernando VI", en VV.AA, La época de Fernando VI: 139-224 Oviedo. Antonio Carrasco Rodríguez, A. 1996. "El Patronato Real en Cataluña, 1715 - 1775". Revista de Historia Moderna 13-14: 95-122. Barrio Gozalo, M. 2001. "El sistema beneficial en la España del siglo XVIII. Cambios y pervivencias". Cuadernos dieciochistas 2: 73-107. Ver, asimismo, Jiménez Sureda, M. 1999. L’Església catalana sota la Monarquía dels Borbons. La catedral de Girona en el segle XVIII. Barcelona. Carreras Panchón, A. Granjel, M. 2005. "Regalismo y policía sanitaria. El episcopado y la creación de cementerios en el reinado de Carlos III". Hispania Sacra 116: 589-624. 
niveles de la sociedad y que podía, en consecuencia, ser portavoz de los intereses de la Corona en distintos ámbitos sociales o territoriales. En la parroquia más recóndita, el párroco se encargaba de hacer llegar a los feligreses las órdenes reales o las disposiciones regias. En las catedrales, en las colegiatas o en la capilla real, obispos, canónigos y capellanes arropaban a la Corona con sermones, cartas pastorales u oraciones fúnebres. La omnipresencia del poder regio contaba, en este sentido, con un potencial aliado en el clero, al que se convertía de forma lenta pero imparable en cuerpo funcionarial al servicio del Estado. ${ }^{5}$ El monarca, a través de la concesión de beneficios parroquiales, canonjías o mitras, buscaba la proliferación de vasallos leales entre los cuadros clericales.

Pero el patronato regio y el manejo instrumental de los nombramientos no deben ser vistos sólo como ejercicios impositivos por parte de la Corona. "Desde abajo", desde los mismos candidatos a piezas eclesiásticas, se formó una cohorte clientelar dispuesta a prestar servicios de control sobre la población, a denunciar abusos en las parroquias, a delatar a disidentes de la línea política marcada desde la Corte o a producir escritos regalistas de todo tipo. Las prestaciones transitaban, pues, en ambas direcciones. ${ }^{6}$

Los eclesiásticos, seculares o regulares, se debatían permanentemente en la obediencia a dos poderes que se pretendían soberanos. ${ }^{7}$ El clero planteaba un importante problema de fidelidad en este periodo de intenso cambio político. La expulsión de los jesuitas en 1767 es un buen ejemplo de ello. ${ }^{8}$ El cuarto voto de obediencia a la

${ }^{5}$ Millet, H./Moraw, P. 1996. "Clerics in the State", en, W. Reinhard (ed.), Power elites and the State building. The origins of the modern state in Europe, $13^{\text {th }}-18^{\text {th }}$ centuries: $174-188$. New York: Clarendon Press. Barrio Gozalo, M. 2001: 79. Giménez, E./ Martínez Gomis, M. 1992. "El episcopado español y la encuesta del Marqués de Ensenada de 1750", en E. La Parra/J. Pradells (eds.), Iglesia, Sociedad y Estado en España, Francia e Italia: 263-299. Alicante.

${ }^{6}$ Cfr. Egido, T. 1989. "Actitudes regalistas de los obispos de Carlos III", en C. Ma . Cremades Griñán (ed.), Estado y fiscalidad en el Antiguo Régimen: 67-83. Murcia.

7 Problema planteado por Blet, P. 1981. "Fidèle au pape, fidèle au roi", en Y. Durand (coord.), Clientèles et fidélités à l'époque moderne. Hommage à Roland Mousnier: 315-332. Paris: PUF.

8 Egido, T./Pinedo, I.1994: Las causas "gravísimas" y secretas de la expulsión de los jesuitas por Carlos III. Madrid: Fundación Universitaria Española. Datos valiosos y referencias de archivo en Pastor, L. Von. 1937. Historia de los Papas desde fines de la Edad Media. Versión de la cuarta edición alemana por el Padre Manuel Almarcha (S.I). Vol. 36: Historia de los Papas en la época de la Monarquía Absoluta: 362-478. Barcelona: Gustavo Gili. 
Santa Sede chocaba con el rechazo creciente de los monarcas a aceptar cualquier manifestación que menoscabara el ejercicio de su soberanía. En términos generales, la Compañía de Jesús cuestionó históricamente el poder absoluto de los reyes, construyó una teoría que anteponía la comunidad eclesiástica a la comunidad política, y una concepción del sistema que, forjado en sus elementos clave durante el siglo XVII, suponía una rémora para la consolidación del pensamiento político secularizado y su práctica, es decir, para la razón de Estado moderna. ${ }^{9}$ Pero la cuestión de los jesuitas, en todo caso, debe ser entendida en el contexto más amplio de la evolución de los sistemas políticos en la Europa del siglo XVIII, que modificaba notablemente los parámetros de las relaciones de la esfera eclesiástica con la política. ${ }^{10}$ Lo que necesitaba el Estado absolutista era un clero adicto, disciplinado, y obediente. Pero, ¿se pudo conseguir esto? Y, si se consiguió, ¿cómo se hizo?

Las investigaciones se han centrado preferentemente en las matrices culturales del regalismo hispano, en su relación o no con el francés, en su componente jansenista o en la falta de éste, pero en raras ocasiones se ha estudiado la práctica cotidiana, política, e institucional del regalismo. Es lo que pretendo aquí. La alta carrera eclesiástica cambió sustancialmente no sólo con el Concordato de 1753, sino también con la intervención del rey y sus ministros en (al menos) tres esferas de actuación que analiza este trabajo.

En primer lugar, un cambio en el reclutamiento clerical a través de la sustitución de los hombres en centros que actuaban como canales hacia la decisión del rey: la Secretaría del despacho de Gracia y Justicia, el confesionario regio, la Cámara de Castilla, y el episcopado, que hacían llegar las noticias sobre los eclesiásticos aptos o meritorios para beneficios eclesiásticos. En segundo lugar, el rey estableció con su clero una relación cuyos caracteres se corresponden con los de las relaciones clientelares. El rey tenía la capacidad para decidir la carrera de un clérigo, mientras que éste tenía que hacer méritos, a través de escritos, o

${ }^{9}$ Rivera García, A. 1999. La política del cielo. Clericalismo jesuita y estado moderno. Hildesheim: Georg Olms. Andrés-Gallego, J. 2003: El motín de Esquilache, América y Europa: 491-528. Madrid: Fundación Mapfre Tavera/Consejo Superior de Investigaciones Científicas.

${ }^{10}$ Para las llamadas relaciones Iglesia-Estado en Austria, Jean Bérenger, J. 2007. Joseph II d'Autriche. Serviteur de l'État: 383-411. Paris: Fayard, en que se discuten el alcance y carácter reales del josefinismo. Para Francia y el galicanismo, Bergin, J. 2004. Crown, Church and Episcopate under Louis XIV. Yale: Yale University Press. en que se expone este tema comprendido en el estudio del ejercicio del derecho de presentación episcopal del rey de Francia. 
servicios políticos, para devolver el favor. Y, por último, se estableció una sutil política que promovía la punición y el detenimiento de las carreras de aquellos que no respondieran a las expectativas regias.

En el ejercicio del patronato regio, la gracia regia aparece como elemento clave de inclusión o exclusión política. Si bien es cierto que los actores del "despotismo ministerial" colocaron unos dispositivos defensores en los puestos por los que se filtraban las informaciones sobre los eclesiásticos aptos para beneficios del Real Patronato, la gracia del monarca, o su negación, se convertía en el tegumento final que protegía al sistema de elementos indeseables, y lo que marcaba, en última instancia, la integración o exclusión de un eclesiástico del sistema político. $^{11}$

\section{EL RECLUTAMIENTO ALTOCLERICAL: EL SISTEMA Y SUS CAMBIOS}

\section{La parcial neutralización del confesor regio}

El confesor del rey, figura clave durante el reinado de Fernando VI, tanto en la configuración del tejido beneficial español, como en gran parte de la vida política de la monarquía, ya había perdido cierto protagonismo cuando Carlos III llegó a Madrid. De hecho, el segundo equipo de gobierno de Fernando VI se había encargado de reducir notablemente su influencia. $^{12}$ No se podía permitir que el confesionario tuviera el poder que había tenido durante su ocupación por el P. Francisco Rávago o sus antecesores de la Compañía de Jesús. ${ }^{13}$

Las funciones del confesor no estaban jurídicamente reguladas. Era fácil que sus acciones pasaran del campo sacramental al político. Así, de las funciones de dirección espiritual que propiamente le correspondían, pasaba a ser consejero personal del monarca gracias al trato frecuente, personal y privilegiado con éste. En este contexto, la

${ }^{11}$ Cfr. Hespanha, A. M. 1993. La gracia del derecho: economía de la cultura en la edad moderna. Madrid: Centro de Estudios Constitucionales. Martínez Ruiz, E. (dir.) 1998

12 Para los cambios ministeriales durante el reinado de Fernando VI, Gómez Urdáñez, J. L. 2001. Fernando VI: 103-121. Madrid: Arlanza. Las actitudes de los contemporáneos, ora lamentando, ora celebrando, la caída del equipo ensenadista se pueden ver en Egido, T. 2002. Opinión pública y oposición al poder en la España del siglo XVIII (1713-1759): 195-235. Valladolid: Universidad de Valladolid-Fundación Española de Historia Moderna [1 $1^{\mathrm{a}}$ ed. 1971].

${ }^{13}$ Alcaraz Gómez, J. F. 1995. Jesuitas y reformismo. El Padre Francisco de Rávago (1747-1755). Valencia: Facultad de Teología. 
práctica sacramental jugaba a favor del confesor, ya que sus opiniones llevaban tras de sí el peso de la conciencia, la moral y la religión. ${ }^{14}$

Su neutralización por los ministros del monarca se convirtió en imperativo político. Carlos III se trajo consigo desde Nápoles a fray José Calzado, franciscano, quien fue su confesor durante más de treinta años. A su muerte en 1761, el rey eligió a su discípulo fray Joaquín Eleta, también franciscano. Estaría en el confesionario hasta su muerte, en 1788. Su influencia no es comparable, ni mucho menos, a la que tuvieron los jesuitas de los primeros Borbones. La personalidad del nuevo monarca, el peso y autonomía de la maquinaria estatal y la influencia de los ministros redujeron su capacidad de actuación.

Anijesuita convencido, fray Joaquín continuó siendo receptor de solicitudes y dispensador de influencias en lo concerniente a provisiones eclesiásticas, como se puede ver en los ricos fondos del Archivo General de Simancas. No obstante, incluso en este estrecho marco, debió compartir su protagonismo con el Secretario de Gracia y Justicia, quien fue aumentando su espacio decisorio durante el periodo. Hacia 1785, según veía el nuncio apostólico, su capacidad de controlar el patronato regio, enorme al comienzo, había pasado en buena parte al secretario. ${ }^{15}$

\section{La Cámara de Castilla y el secretario de Gracia y Justicia}

La Cámara de Castilla tenía un importante papel en la gestión de la gracia regia. Era, en palabras de Philippe Loupés, el "lugar neurálgico en el que confluyen las redes de relaciones personales por las cuales, tanto o más que por decisiones mandatorias, se gobierna el reino". ${ }^{16}$ Los camaristas, reducido grupo de composición variable, formaban la cúpula del Consejo de Castilla. A través de consultas elevadas al rey orientaban un aspecto básico de la organización política de la monarquía: la

${ }^{14}$ Martínez Peñas, L. 2007. El confesor del rey en el Antiguo Régimen: 764. Segovia/Madrid: Colegio Universitario Santo Domingo de Segovia-Editorial Complutense.

15 Sierra Nava, L. 1984. "Una década de política religiosa de Carlos III vista por los ojos de un nuncio y un abate romanos (1776-1785)", en Cuadernos de investigación histórica 8: 171-202. Véase también Gómez Rivero, R. 1999. El Ministerio de Justicia en España (1714-1812): 611 ss. Madrid: Centro de Estudios Políticos y Constitucionales.

${ }^{16}$ Loupés, Ph. 2000. "Los mecanismos de la Cámara de Castilla en el siglo XVIII. La selección del alto personal judicial", en J. L. Castellano/J. P. Dedieu/Ma V. López Cordón (eds.), La pluma, la mitra y la espada. Estudios de Historia Institucional en la Edad Moderna: 52. Madrid: Universidad Burdeos/Marcial Pons. 
economía de la gracia. En cada vacante de una pieza eclesiástica del Real Patronato, elevaban una propuesta de candidatos, sugiriendo algunos nombres para la elección del monarca. Para formar las ternas, los camaristas se valían de informaciones de diversa procedencia, siendo las más conocidas las relaciones de méritos de los mismos pretendientes, los informes de obispos o las recomendaciones de particulares. $^{17}$

En la segunda mitad del siglo XVIII se produjo una notable variación en el reclutamiento de los consejeros del Consejo de Castilla, incrementándose progresivamente el número de abogados, que sustituían a los letrados provenientes de los Colegios Mayores. ${ }^{18}$ Suponía un cambio importante, también, en la extracción social de los camaristas de Castilla. Y en su perfil político. A partir del acceso del conde de Aranda a la presidencia del Consejo(1766), se modificaron ostensiblemente los criterios de reclutamiento de los magistrados, siendo, en adelante, preferentemente "amantes de la regalía" ${ }^{19}$

El Secretario del despacho de Gracia y Justicia hacía de pantalla entre la Cámara de Castilla y el monarca. El rey despachaba los asuntos eclesiásticos con el secretario. La secretaría, ocupada sucesivamente por hombres adictos a la política de Carlos III, como Manuel Roda (17651782) $y$ el conde de Floridablanca (1782-1790), comunicaba directamente con el rey y actuaba como filtro de las consultas que se elevaran por parte de la Cámara, con lo que se abría la posibilidad de que el secretario influyera en la decisión final. ${ }^{20}$

La percepción de los cambios políticos en los pretendientes a piezas eclesiásticas del Real Patronato

17 Enríquez Agrazar, L. 2006. De colonial a nacional: la carrera eclesiástica del clero secular chileno entre 1650 y 1810. México D.F.: Instituto Panamericano de Geografía e Historia. Carrasco Rodríguez, A. 1997. El Real Patronato en la Corona de Aragón. El caso catalán, 1715 - 1788: 59. Alicante: Universidad de Alicante.

18 Dedieu, J. P. 2005. "La muerte del letrado", en F. J. Aranda Pérez (coord.), Letrados, juristas y burócratas en la España Moderna: 479-512. Cuenca: Universidad de Castilla La Mancha. Molas Ribalta, P. 1996. "La estructura del Estado y las elites de poder", en A. Guimerá (ed.), El reformismo borbónico. Una visión interdisciplinar: 61-73. Madrid: Alianza.

${ }_{19}$ Molas Ribalta, P. 2000. Los magistrados de la llustración. Madrid: Centro de Estudios Políticos y Constitucionales.

${ }^{20}$ González Fuertes, M. A. 2003. La organización institucional de la Cámara de Castilla en la época borbónica: 59. Córdoba: Servicio de Publicaciones de la Universidad. Para Indias, ver Enríquez Agrazar, L. 2006: 49. 
¿Cómo se hacían sentir estas modificaciones entre los pretendientes a piezas eclesiásticas? La estructura de oportunidades que surgía de los cambios de equipos ministeriales era exclusiva para aquellos que se hubieran destacado en la línea de política eclesiástica que se implantaría desde los años sesenta en adelante. Los movimientos en la cúpula del sistema se sustanciaban en la base en forma de consultas y nombramientos para piezas eclesiásticas. José Gonzalo Mendoza, prior del Priorato Real de Grou, lo exponía del modo siguiente cuando, en carta a Manuel Roda, pedía un ascenso en su carrera:

"Veintidós años hace, que no ceso de pretender cargo de justicia, y de razón un acomodo correspondiente a la gravísima necesidad de mi casa, y familia: mis defectos para no conseguirlo durante el gobierno pasado fueron no tener beca, ser pariente del venerable señor Juan de Palafox y Mendoza, haber hecho un tío mío carnal lectoral de la Santa Iglesia de Osma con comisión apostólica los procesos de la causa de su beatificación, y haber defendido otro tío carnal carmelita descalzo (que aún vive) diferentes pleitos, y negocios en nombre de su religión contra la de la Compañía de Jesús, siendo uno de ellos para impedir la fundación de un colegio en el sitio donde San Ignacio recibió el balazo, inmediato a la Huerta de las monjas carmelitas de Pamplona, de que es buen testigo el ilustrísimo señor Arzobispo de Tebas.

Luego, que fue nombrado Presidente el excelentísimo señor conde de Aranda, se me consultó para el arcedianato de Chinchilla, dignidad de la Santa Iglesia de Cartagena, y posteriormente se me dio el Real Priorato de Grou"21

Por tanto, si no dirigidos expresamente a este fin, los cambios expuestos coadyuvaron a la labor de profilaxis de los canales de influencia que llegaban a la persona regia. El regalismo impregnaba así, mediante estos dispositivos y mecanismos, a todo ese conjunto de organismos que concurrían en las provisiones eclesiásticas: el confesor, los secretarios, la Cámara de Castilla y los obispos. Sus efectos en la elección de los eclesiásticos que habían de ocupar las piezas de Real Patronato ya eran aireados por los opositores al gobierno mediante la literatura propagandística clandestina:

"Hoy para las mitras se propone / no al que, libre, la Cámara quisiera, / sino al benemérito supone / de Roda y Osma el arte

${ }^{21}$ AGS (Archivo General de Simancas), Gracia y Justicia, leg. 364. Carta de Carta de José Gonzalo Mendoza Leiva, prior de San Martín de Grou, a Manuel Roda, secretario de Gracia y Justicia. Madrid, 19 de mayo de 1771 
lisonjera / al que siendo tomista más se encone / contra la religión más verdadera / debiendo el que pretende ser tomista / o un acreditado jansenista" 22

Ahora bien, los que no pudieran acreditar tal filiación debían buscar otras vías para pasar por los filtros dispuestos por el monarca y sus ministros. La desaparición de las menciones a los colegios jesuitas en las relaciones de méritos de los pretendientes es uno de los ejemplos más claros. Las relaciones en sí no muestran la ocultación del pasado del pretendiente. Para esto, es necesario cruzar esta documentación con otras fuentes, y escudriñar en la vida documentada de los actores, descubrir sus orígenes sociales y sus ámbitos relacionales previos. Al realizar este ejercicio rastreando la documentación existente sobre alto clero de origen vasco, he podido cómo varios sujetos que hicieron carrera eclesiástica durante los años centrales del reinado de Carlos III se vieron obligados a borrar de sus expedientes el tiempo pasado estudiando con los padres de la Compañía.

José Ignacio Ansótegui levantó en la Secretaría del Real Patronato, el 4 de julio de 1781, una relación de méritos que iba a presentar cada vez que pretendiera una ración, canonjía o dignidad de alguna catedral. En el documento se afirmaba que estudió en la universidad de Valladolid, por la que fue bachiller en Filosofía y Teología, y en la de Toledo, en la cual se licenció en Cánones; que sustituyó varias cátedras en la universidad de Valladolid, que se hallaba ordenado de presbítero, que había opositado a una canonjía doctoral de la colegiata de San Ildefonso, y que fue presentado por el rey para una canonjía de la catedral de Calahorra en $1776 .{ }^{23}$

Estaba ocultando una parte importante de su vida. Era hijo de una familia de estrechas conexiones con los jesuitas. Su difunto tío, Juan Fernando Barroeta Ansótegui, consejero del Consejo de Órdenes militares, ya había sido tildado de projesuita en un informe remitido a Manuel de Roda en $1765 .{ }^{24}$ En el pueblo del que era natural, Marquina (Vizcaya), se dieron resistencias a la lectura de la pragmática de la expulsión de los padres de la Compañía, ya que sus habitantes se

${ }^{22}$ Cit. Olaechea, R. 1983. "Política anticolegialista del gobierno de Carlos III". II Simposio sobre el Padre Feijoo y su siglo: 223. Oviedo.

${ }^{23}$ AGS, Gracia y Justicia, leg. 323. Datos cotejados con los de Arribas Arranz, F. 1963. Relaciones y justificantes de méritos y servicios de catedráticos, profesores y opositores a cátedras, Universidad de Valladolid: 14. Valladolid.

${ }^{24}$ Fichoz: 012218. 
mostraban contrarios al extrañamiento. ${ }^{25}$ El archivo parroquial de la localidad custodia, en su fondo de "papeles varios", nutrida información de la situación de los jesuitas en el exilio y algunas cartas de éstos a sus allegados. ${ }^{26}$ En definitiva, la zona de la que provenía guardaba, por lo general, notable vinculación con la Compañía.

Pero José Ignacio no sólo había nacido en Marquina (lo cual, en cualquier caso, tampoco significaría una orientación concreta a fortiori), sino que había participado en su vida social de una forma significativa. Según consta en su expediente universitario, recién acabados sus estudios de Filosofía en el colegio de la Compañía de Jesús de Valladolid, obtuvo del obispo de Calahorra licencia para predicar el sermón del día de San Ignacio de 1765 en su villa natal. ${ }^{27}$ Antes de estas fechas, había cursado estudios de Filosofía en el colegio de los jesuitas de Pamplona ${ }^{28}$. Todo se omitía, sin embargo, en su relación de méritos, para intentar pasar por los filtros dispuestos en el sistema.

Este fenómeno de ocultación, bastante generalizado, es elocuente del eventual dominio del antijesuitismo militante en las altas esferas políticas. Por ello, Joaquín Ignacio Murúa, descendiente de una familia principal de Vergara (Guipúzcoa), tampoco quería que los tres años que pasó en el colegio de la Compañía de Jesús de Pamplona figuraran en su relación de méritos. Cuando levantó ésta en 1786, dejó constancia de toda su carrera académica: estudios de Cánones en Valladolid, primero, y en la universidad de Oñate, después. Afirmaba también que en 1779 ganó la oposición a la canonjía doctoral de la catedral de Calahorra, y aprovechaba la ocasión para adjuntar unas testimoniales emitidas por el obispo en las que se le presentaba como miembro de "una de las familias más distinguidas de la Provincia de Guipúzcoa". ${ }^{29}$ Si bien es cierto que en 1788 sería nombrado por el rey para una dignidad de la catedral de Burgos (gracias, entre otras cosas, a las recomendaciones que para sus candidaturas hacía su obispo ${ }^{30}$ ), lo importante en este trabajo es mostrar cómo, por temor a ser clasificado entre los partidarios de los jesuitas,

${ }^{25}$ Uriarte Astarloa, J. Ma. 2002. Pablo Pedro Astarloa: biografía: 48.

Durango: Museo de Historia.

${ }^{26}$ Archivo Histórico Eclesiástico de Vizcaya (AHEV), Marquina - Xemein, Santa María, Papeles Varios, microfilm 9A458, signatura 2603.

${ }^{27}$ Archivo Universitario de Valladolid (AUV), leg. 533, exp. 16.

28 Ídem.

${ }^{29}$ AGS, Gracia y Justicia, leg. 328.

30 Ibídem. Consulta de la Cámara de Castilla sobre la provisión del arcedianato de Berberiego, dignidad de la catedral de Burgos. Madrid, 28 de febrero de 1787. El ejemplo es particularmente interesante, en cuanto indica que era posible neutralizar el pasado jesuita por medio de una recomendación 
prefirió obviar tres años de su vida que en su expediente académico de la universidad de Valladolid quedan claramente documentados. ${ }^{31}$ Los ejemplos podrían multiplicarse.

Los mecanismos empleados por la Corona para el control ideológico del alto clero hacían que ni siquiera un pasado académico de otro signo fuera garantía. Informadores adeptos a la política de Carlos III y sus ministros, como eran algunos obispos nombrados por el mismo rey, podían detener una prometedora carrera. José Uríen lo pudo comprobar por sí mismo. Tras doctorarse en Leyes y Cánones por la universidad de Valladolid, fue elegido en 1747 provisor y vicario general del obispado de Solsona por José Mezquía. En 1748, fue nombrado para el deanato de la misma catedral, nombramiento que quizás se debió al control de Francisco Rávago sobre el confesionario regio. ${ }^{32}$ El obispo informaba puntualmente sobre sus virtudes y le recomendaba, en sucesivos informes enviados a la Secretaría del Real Patronato de Aragón, para canonjías y dignidades de las primeras catedrales de España. ${ }^{33}$ Podía llegar a tener opciones de ascender al episcopado. El obispo le colocaba en primer lugar para ocupar mitras, cuando respondía a la Real Orden de 2 de agosto de 1760 por la que se pedían nuevos informes:

"El doctor José Antonio Uríen, natural de Bilbao, edad de 42 años cumplidos, estudió en la Universidad de Valladolid; y se graduó en ella de bachiller en Cánones; y de Licenciado y doctor en la de Ávila. Pasó después a Madrid, en donde se dedicó a la jurisprudencia práctica; se recibió de abogado en el año de 1742; y se ordenó de presbítero en el de 44, siendo a la sazón provisor de Ceuta: lo es de este obispado de Solsona desde febrero de 47, habiendo sido nombrado Juez Sinodal en su sínodo diocesano, y examinador sinodal en los sínodos de Barcelona y Gerona, es Deán de esta catedral desde 1748, desde cuyo tiempo ha residido continuamente su Prebenda, manifestando en lo mismo, y en otras cosas, lo ajustado, y aun delicado de su conciencia. También se halla nombrado revisor de libros por el Santo Tribunal de la Inquisición de Barcelona en todo su distrito desde el año de $1750^{\prime \prime 34}$

Sin embargo, su protector moriría en septiembre de 1773 para ser sucedido por fray Rafael Lasala, hombre formado en otros esquemas

\footnotetext{
${ }^{31}$ AUV, leg. 415, expedientes 97 al 106.

${ }^{32}$ AGS, Gracia y Justicia, leg., 330.

${ }^{33}$ AGS, Gracia y Justicia, leg., 590.

${ }^{34}$ AGS, GJ, leg. 590.
} 
eclesiológicos. ${ }^{35}$ En 1777, éste enviaba un informe a la Secretaría del Patronato, en que dejaba caer que "el citado Uríen ha andado enlazado con Jesuitas, y fautores suyos, sin embargo de que sus principios fueron de doctrina tomística en un convento de mercedarios". ${ }^{36}$ Nunca más fue ascendido en su carrera.

Las actitudes de rechazo hacia el pasado formativo propio contrastan con los empeños por mostrar a los ministros o al confesor del rey elementos que les pudieran agradar. Entre éstos, destaca la formación académica en centros no relacionados con los jesuitas o las comisiones llevadas a cabo por orden de la Corona o los obispos. Por ejemplo, el deseo de José Vicente Junguitu, protegido del arzobispo de Zaragoza Juan Sáenz Buruaga, de hacer constar en su relación de méritos que había estudiado Filosofía y Teología "en el Estudio General de SANTO DOMINGO" de la ciudad de Vitoria. ${ }^{37}$ En su primera candidatura a una canonjía de la colegiata de Vitoria se le nombró para ésta, pese a ser propuesto en segundo lugar por la Cámara de Castilla. ${ }^{38}$

\section{FAVORES, SERVICIOS, ASCENSOS: LA RELACIÓN DEL REY CON EL ALTO CLERO SECULAR}

En 1766, retomando una orden del rey Juan I de Castilla, Carlos III emitía un Real Decreto sobre el cuidado que los prelados debían poner en que los clérigos y religiosos no hablaran mal de las "Personas Reales, Estado o Gobierno". Su enunciado es significativo:

"El buen exemplo del Clero secular y Regular trasciende a todo el cuerpo de los demás vasallos en una nación tan religiosa como la Española: el amor y el respeto á los soberanos, a la familia real, y al gobierno es una obligación que dictan las leyes fundamentales del Estado, y enseñan las Letras Divinas a los súbditos como punto grave de conciencia: de aquí proviene que los Eclesiásticos, no sólo en sus sermones ejercicios espirituales y actos devotos deben infundir al pueblo estos principios, sino también, y con más razón, abstenerse ellos mismos en todas ocasiones, y en las conversaciones familiares, de las declamaciones y murmuraciones depresivas de las personas del

${ }^{35}$ León Navarro, V. 1999. "Rafael Lasala y Locela, obispo auxiliar de Valencia. Su postura ante la extinción de los jesuitas". Revista de historia moderna. Anales de la Universidad de Alicante 17:353-372

${ }^{36}$ AGS, Gracia y Justicia, leg., 318.

${ }^{37}$ En mayúsculas en el documento. AGS, Gracia y Justicia, leg. 316.

${ }^{38}$ AGS, Gracia y Justicia, leg. 312. 
Gobierno, que contribuyen a infundir odiosidad contra ellas, y tal vez dan ocasión a mayores excesos..."39

La mentalidad discursiva que subyace al texto revela el objetivo de poner la jerarquía eclesiástica al servicio del gobierno absoluto para el control del clero en todos los niveles de su organigrama jerárquico. Como se verá, los que cumplieran con los deberes que les eran asignados recibirían del patrono un premio a su medida, mientras que los que desobedecieran verían caer sobre ellos todo el peso de la sutil maquinaria represiva del sistema.

Juan Sáenz de Buruaga logró ascender hasta la mitra de Zaragoza gracias a una multiplicidad de factores de los que no es posible dar cuenta detallada aquí. Baste con decir que fue acogido y protegido por su tío homónimo en Madrid, financiero con título de secretario del rey Felipe V. Pasó a estudiar con los capuchinos de San Antonio del Prado de Madrid, primero, y al colegio de Santo Tomás de Madrid, después. Más tarde acudió a la universidad de Alcalá de Henares, y, tras obtener el bachillerato en Teología, ingresó en el colegio mayor de San Ildefonso. En 1735 se doctoró en la misma facultad, y ocupó finalmente una cátedra de Artes. ${ }^{40}$ Parece que estos ámbitos de estudio y sociabilidad le fueron predisponiendo hacia un servicio a la monarquía que, sin grandes inconvenientes, se puede calificar de clientelar, en tanto que iba a obtener, gracias a ellos, un gran premio del gran patrono: el rey.

En 1740, dos años después de obtener una canonjía magistral en la catedral de Segovia, publicó una oración fúnebre en memoria de la reina Mariana de Neoburgo, que más allá de la temática concreta de la muerte de la soberana, constituye un clarísimo ejemplo de sacralización de la Corona, de retrato elogioso de la familia real. ${ }^{41}$ Por otra parte, antes

${ }^{39}$ Novísima Recopilación: libro I, título VIII, ley VII. Real Decreto de 14 de septiembre de 1766, inserto en Cédula del Consejo de 18 del mismo mes

40 Todos los datos en Vergara, A. 1985. Sáenz de Buruaga. Un linaje histórico en Cigoitia: 12-33. Vitoria: Caja Provincial de Álava-Arabako Kutxa. Gutiérrez Torrecilla, L. M. 1992. Catálogo biográfico de los colegiales y capellanes del colegio mayor de San Ildefonso de la Universidad de Alcalá (1508-1786): 94. Alcalá de Henares. Sermón fúnebre en las solemnes exequias que por la alma de su difunto amo, el ilustrísimo, y reverendísimo señor don Juan Sáenz de Buruaga, Arzobispo de Zaragoza, celebró su agradecida familia el día 12 de junio del año 1777, en la Iglesia del Real Seminario de San Carlos. Zaragoza: Imprenta de Juliana Destre, Viuda de José Fort.

${ }^{41}$ Oración fúnebre, triste llanto, que en las reales honras, que el día 12 de septiembre de 740 hizo la muy noble, y muy leal ciudad de Segovia, con asistencia de su IIImo Cabildo, a la augusta memoria de la Reyna Nuestra Señora Doña Mariana de Neoburg, dixo el Doct. Don Juan Sáenz de Buruaga, 
de los años sesenta, ya se había destacado en el combate a la introducción de la devoción al Sagrado Corazón y, por ende, al imaginario de la Compañía de Jesús en España ${ }^{42}$ Logró así, y a través de las recomendaciones que obtenía del obispo de Segovia, ser ascendido en 1762 a la mitra de Lugo. ${ }^{43}$ Nombrado, muy probablemente mediando en ello su antijesuitismo, arzobispo de Zaragoza, fue consejero del Consejo Extraordinario ${ }^{44}$. Como era de esperar, en la campaña de extinción de la Compañía promovida por el gobierno de Carlos III, aparece como uno de los obispos que secundaron la medida sin ningún tipo de reservas. ${ }^{45}$

Los dispositivos para controlar las carreras hechas bajo el patronato regio, para adoctrinar a los altos eclesiásticos y ponerlos a su servicio, tuvieron que tener algún efecto. Cuesta explicar de otra forma cómo algunos eclesiásticos, habiendo pertenecido al partido jesuita, se destacaban redactando escritos defensorios de los derechos del rey, que aprovechaba su predicamento entre los fieles transformando su tradicional papel de élite letrada en intelectualidad orgánica de la monarquía. Es el caso de José Luis Mollinedo, nombrado obispo de Palencia en 1780. Pese a que su hermano Nicolás, quien hizo carrera en la Secretaría de Estado, era caracterizado por el agente en Roma como hombre "nada adicto a los jesuitas" ${ }^{\text {, }}$, y su hermano Manuel colaboraba en su expulsión de Vizcaya, él era acusado, en un informe de 1765, de pertenecer al partido jesuita. ${ }^{47}$ Es difícil saber si sus sentimientos, o su filiación política, seguían siendo los mismos cuando fue nombrado obispo, si el nombramiento fue resultado de las influencias de su familia en la corte, o si la calificación de afecto a la Compañía de Jesús tenía algún fundamento. ${ }^{48}$ Lo que queda claro es que, desde su nueva

Colegial Mayor de San Ildefonso, Catedratico de Philosophia de la Universidad de Alcalá, Canónigo Magistral de la Santa Iglesia Catedral, examinador sinodal de este obispado, etc., S.I : s.n., s.a.

${ }^{42}$ Fichoz: 016540

${ }^{43}$ AGS, Gracia y Justicia, leg., 318.

${ }^{44}$ Formado por el rey, en principio para la investigación de los motines de 1766, y progresivamente ampliado numérica y temáticamente hasta abarcar su jurisdicción la administración de los bienes de los jesuitas expulsos y asuntos reservados. Egido, T./Pinedo, I.1994: 26-37.

${ }^{45}$ Egido, T. 1989.

${ }^{46}$ Olaechea, R. 1981: 218-219.

${ }^{47}$ Olaechea, R. 1983: 239. Sobre el citado informe, Irles Vicente, Ma . C. 1996. "Tomismo y Jesuitismo en los Tribunales españoles en Vísperas de la expulsión de la Compañía". Revista de Historia Moderna 15: 73-99.

${ }^{48}$ Zuluaga Cítores, Á. 1999. Sebastián De La Quadra Primer Marqués De Villarías (1687-1766) Secretario De Estado En El Reinado De Felipe V, 
posición, procuró servir al rey con las armas que tenía en la mano, actuando de correa de transmisión de los intereses de la Corona.

Es buen ejemplo de ello la carta pastoral que publicó en 1786 sobre la obligación de pagar los diezmos, así como los impuestos debidos al rey. Recomiendo se lea teniendo en mente la Real Orden transcrita al comienzo de este epígrafe. El escrito va destinado, como carta pastoral, "a los párrocos, sacerdotes, beneficiados, confesores, predicadores, seculares y regulares, y demás fieles de el obispado de Palencia" ${ }^{49}$, a los que el prelado debía dirigir como pastor. Le había sido encomendado, por el conde de Floridablanca, salir al encuentro de una serie de proposiciones que cuestionaban el poder absoluto del monarca, y alertar sobre una de ellas, dirigida "a debilitar o destruir toda potestad o superioridad entre los Hombres, a sacudir todo yugo de sujeción en la tierra, a favorecer a los que no obedecen a las Potestades Superiores, y resisten a la fuerza de las Leyes, y a tranquilizar las conciencias de los malos, amortiguando sus remordimientos, y por decirlo así, contribuir a que hagan paz los Impíos con los Pecados"

Las proposiciones de tal doctrina, un total de 18 , se resumían de la siguiente manera: ningún hombre, ni siquiera el obispo ni el rey, tiene potestad sobre otro a no ser que éste dé su consentimiento expreso. Lo contrario es tiranía. Consecuentemente, las leyes tributarias impuestas por los soberanos son puramente penales, por lo que no obligan en el fuero de la conciencia. Por lo tanto, los que practican el contrabando u otros tipos de fraude económico no están moralmente obligados a la restitución de las cantidades defraudadas. Igualmente, los recaudadores de rentas reales, los guardas y otros empleados del monarca que permitan en algún caso el contrabando no cometen ninguna falta. En definitiva, las leyes no obligan en la conciencia o en la obligación moral hacia el soberano. ${ }^{51}$

Estas ideas desmontan desde su raíz toda la base teórica del absolutismo. El obispo las vinculaba, en su primera formulación de ausencia de potestad de un hombre sobre otro, a "los Herejes Lutero y

Muskiz: Ayuntamiento de Muskiz/Petronor, ofrece una cantidad considerable de datos sobre su familia materna.

${ }^{49}$ Mollinedo, J. L. 1786. Carta pastoral del Ilustrísimo Señor Don Joseph Luis de Mollinedo Obispo de Palencia, del Consejo de SM y caballero de la distinguida orden de Carlos III, Conde de Pernía \&c. Valladolid: Viuda e Hijos de Santander. Esta carta pastoral puede estar inspirada por la corona. Apoya esta idea su radical semejanza con otras cartas pastorales publicadas por otros obispos en el mismo año.

${ }^{50}$ Ibídem, pp. 4-5

${ }^{51}$ Ibídem, pp. 7-9 
Calvino, asentando, que todas las Leyes comprendidas en el Derecho Canónico y Civil, eran nulas por defecto de potestad en quien las puso". Como es sabido, ambos negaban el poder divino de los reyes, punto en el que coincidían con la doctrina después formulada por los jesuitas. No hace falta insistir en que, en un momento de afirmación del poder regio, este supuesto debía ser deslegitimado rápidamente.

Respecto al segundo grupo de ideas, referente al derecho de evadir las cargas fiscales de la Corona, se conectan con Wiclef y Juan de Wesalia, en lo eclesiástico, y con Judas Gaulanita, "que enseñaba a los judíos no estar obligados a pagar el tributo al César", en cuanto a lo civil. En cambio, los apóstoles, en la interpretación del prelado, enseñan que se debe una obediencia absoluta al que tenga el poder directamente transmitido por Dios. Y la potestad del rey viene directamente de Dios. Ya lo había dicho San Pablo, en su Epístola a los Romanos, cuando mandó que todo hombre "obedezca y viva sujeto a las potestades superiores; porque toda potestad es de Dios (...) por lo que, el que resiste a esta ordenación, se adquiere la condenación eterna; y por esto les aconseja, que estén sujetos y obedezcan a las potestades superiores, no sólo por el castigo, sino también por lo que les interesa a su conciencia". No cabe hablar de poder espiritual y temporal, como afirma "la misma Carta, que habla de una y otra potestad, cuando dice que estén súbditos a toda sublime Potestad, y explica que no hay Potestad sino de Dios". Por todo ello, el obispo encarga a sus

"Carísimos Hermanos, a quienes está confiada la predicación del Evangelio, y dirección de los Fieles que en los Púlpitos y en todas partes les aconsejéis [a los fieles], se guarden mucho de caer en la servidumbre del pecado, de que fueron libres por el Bautismo, y les hagáis entender, que sólo esta esclavitud y servidumbre es la que se opone a la libertad verdadera del Cristiano, y no la sujeción y subordinación que debe tener todo hombre á las Potestades Superiores de la República; que antes bien su misma profesión de Cristianos los empeña, a ser más obedientes y puntuales en la observancia de las Leyes humanas; y les procuréis persuadir, que la libertad Cristiana no consiste en la omnímoda y absoluta independencia, que quieren los Protestantes, sino en aquella libertad que explica el Apóstol: Libres de la esclavitud del pecado, habéis pasado a ser siervos de la Justicia"

Todo el escrito se dirige a refrendar la "declaración de nuestro Piadoso Monarca; que su intención y deseo, como Legislador y como soberano conservador de las Leyes, es de que obliguen a sus Vasallos al positivo cumplimiento en ambos fueros; y que la pena sólo es medio para 
hacerlos cumplir, y no objeto alternativo de las mismas Leyes". Por esta razón, los contrabandistas están obligados a restituir lo defraudado a la Hacienda Real, "pues los impuestos y tributos son verdaderamente del Rey como (...) explicó nuestro redentor Jesucristo, cuando le preguntaron los Fariseos, si era lícito pagar al César (...) Del César son, según la verdad Divina, los impuesto y tributos, y no de los defraudadores".

Estas manifestaciones se enmarcan en la relación de patronazgo que el monarca establece con la jerarquía eclesiástica, que en retribución moral de la posición alcanzada debe poner al servicio de éste su capacidad persuasiva a través de la reconvención a sus clérigos. José Luis Mollinedo llamaba al final de su escrito a la delación de todos aquellos contraventores de la ley. Esta práctica de la delación, y la de la posterior punición, estaba siendo intensamente utilizada con los eclesiásticos disidentes desde algunos años antes, como se verá en las páginas siguientes.

\section{LOS MECANISMOS DE DEFENSA REGALISTA: DELACIÓN, PUNICIÓN Y REHABILITACIÓN POR LA GRACIA REGIA}

En 1767, recién expulsados los jesuitas, Agustín Uriarte se encontraba en Zaragoza sirviendo su destino como inquisidor. Pertenecía a una familia de la nobleza tradicional de Álava y Navarra, bien conectada con círculos de poder locales y centrales. Tenía, además, una trayectoria importante a sus espaldas: colegial del colegio mayor de San Bartolomé de Salamanca, ciudad en cuya universidad se licenció en Leyes en 1738, había sido llevado como provisor y vicario general por Felipe de los Tueros Huerta, recién nombrado arzobispo de Granada. Éste también había realizado sus estudios en Salamanca, licenciándose igualmente en Leyes. ${ }^{52}$ Lo más probable es que por conducto de Juan Antonio Tueros, también colegial de San Bartolomé y sobrino del arzobispo, éste tuviera noticia de Agustín Uriarte. No dispongo de materiales para exponer estos detalles o realizar afirmaciones categóricas sobre el caso. Sin embargo, el empleo de vicario general, otorgado siempre libremente por el prelado, revela la existencia de una relación anterior. Y no una relación cualquiera, ya que se trataba de un puesto de alta responsabilidad. Comportaba, o podía comportar, además, una afinidad ideológica entre prelado y provisor. ${ }^{53}$ Por lo tanto, cabe decir

52 Todos los datos proceden de Carabias Torres, A. 1991. "Catálogo de colegiales del Colegio mayor de San Bartolomé (1700-1840)". Studia Histórica. Historia Moderna IX: 43-88.

${ }_{53}$ Dedieu, J. P. 2005. "Pour une approche relationnelle de l'épiscopat: l'Espagne du XVIIle siècle", en Sous le sceau des Réformes / Au contact des Lumières, Hommage à 'Philippe Loupés: II, 19-30. Burdeos: Presses 
que, por la misma mecánica del nombramiento, en la que primaba la existencia de una relación anterior, Felipe de los Tueros, Juan Antonio Tueros y Agustín Uriarte pertenecían a un mismo mundo cultural, fraguado en gran parte en el colegio mayor de San Bartolomé.

Partiendo del trampolín hacia la jerarquía que suponía ser nombrado provisor de un arzobispado, Agustín Uriarte parece haber hecho carrera a la sombra del confesionario regio. Obtuvo del rey, en fecha anterior a 1746, la dignidad de tesorero de la colegiata de Santillana. En 1747 fue nombrado fiscal de la Inquisición de Zaragoza, con lo que dejó de servir su prebenda en la colegiata. El cabildo de Santillana protestó al considerar que Agustín Uriarte no debería de percibir los frutos de su prebenda, ya que casi nunca la había residido. El rey, sin embargo, dispuso en 1755 que se le acudiera a pagar puntualmente, ya que había obtenido un indulto apostólico de manos del nuncio. ${ }^{54} \mathrm{Y}$, entre hecho y hecho, algunos datos que hablan sobre sus contactos en la corte. Primero, en abril de 1752, pidió al rey que se le otorgara licencia para permutar su prebenda en Santillana. El P. Rávago medió decisivamente para obtener el asenso real. ${ }^{55}$ En septiembre del mismo año, el confesor volvió a intervenir para que a Miguel Uriarte, hermano de Agustín, le fueran conferidos dos beneficios eclesiásticos de real presentación en Navarra. ${ }^{56}$ Sabemos, gracias al trabajo de José Francisco Alcaraz, que durante la permanencia del jesuita en el confesionario fue él quien controló el sistema beneficial. Para ello se valía, entre otros medios, de los informes enviados por los prelados y de recomendaciones enviadas por sus correligionarios de la Compañía de Jesús. ${ }^{57}$ De forma mediata o inmediata, el confesor jesuita aparece, pues, como principal valedor de las aspiraciones de Agustín Uriarte y sus allegados. Vemos tejerse así una red de solidaridades y valimientos sobre los que se desarrollan carreras, ideas y actitudes de amplio alcance.

Como decía más arriba, para Carlos III (o para su equipo ministerial) la expulsión de los jesuitas pudo ser la eliminación de un posible obstáculo a su gobierno, así como un paso conjunto con el resto de las monarquías absolutistas en su ofensiva contra las órdenes regulares. Pero había riesgos, al mismo tiempo. Debían ser conscientes

universitaires de Bourdeaux. Irigoyen López, A. 2008. "Un obispado para la familia: Francisco Verdín Molina, prelado de Guadalajara y Valladolid en la segunda mitad del siglo XVII". Historia Mexicana LVIII/2: 557-593.

${ }^{54}$ AHN, Consejos, leg. 15349, exp. 38.

${ }^{55}$ AGS, Gracia y Justicia, leg. 535.

${ }^{56}$ AGS, Gracia y Justicia, leg. 330.

${ }^{57}$ Alcaraz Gómez, J. F. 1995. 
de que en ciertos círculos sociales arraigaba una subcultura que tenía a los jesuitas y todo su imaginario como referente. Este magma subcultural impregnaba en alguna medida las redes de relaciones que, del mismo modo, se instrumentalizaban para el medre en la carrera eclesiástica. El ejemplo que he comenzado a desarrollar sirve de guía. Cuando Agustín Uriarte dejó el provisorato del arzobispado de Granada, el arzobispo nombró para el mismo cargo a su sobrino Juan Antonio. Poco después, en 1744, el prelado impuso su nombramiento para la canonjía doctoral de Granada, pese a la fuerte resistencia de otro opositor a la prebenda, que consideraba que la falta de edad de Tueros invalidaba sus ejercicios de oposición. De nuevo, un indulto apostólico, la aprobación del confesor jesuita (en este caso el P. Févre) y, después, el asenso real, jugaron a favor del grupo. ${ }^{58}$

Las cosas parecían ir bien, por lo tanto, para Agustín Uriarte y Juan Antonio Tueros, hasta mediados de los años sesenta. El primero continuó sirviendo su destino en la Inquisición de Zaragoza mientras cobraba los frutos de una dignidad eclesiástica que no residía. El segundo, mientras tanto, había conseguido ser nombrado canónigo de la catedral primada de Toledo durante el crepúsculo del dominio del $\mathrm{P}$. Rávago en el confesionario regio, para después pasar a ser provisor del mismo arzobispado en 1757, y dignidad de maestrescuela de la misma catedral en 1761, con Carlos III ya en el trono ${ }^{59}$. Sin embargo, los dos eclesiásticos que otrora compartieran aulas, colegio mayor y, seguro, valores, cultura e ideas, verían su situación y futuro cambiar a consecuencia de una consulta elevada por el Consejo Extraordinario el 17 de noviembre de 1767 a Carlos III.

Los dos estaban acusados de participación en tramas conspirativas contra el gobierno a causa de su (ahora revelado) filojesuitismo. Juan Antonio Tueros fue acusado de haber fomentado revelaciones sobre la posible vuelta de los jesuitas entre las religiosas del convento de San Torcuato de Toledo, "para hacer odioso, y aborrecible el Gobierno, capaces de inspirar a los Pueblos horror, y de faltarle al respeto". ${ }^{60}$ Su carrera hacia el episcopado fue interrumpida de inmediato. En realidad, parece que fue interrumpida algo antes, cuando Manuel Roda accedió a la secretaría de Gracia y Justicia en 1765, ya que Juan Antonio sería propuesto en primer lugar por la Cámara de Castilla para el obispado de Barcelona y rechazado por el rey en $1766 .{ }^{61}$

\footnotetext{
${ }^{58}$ AGS, Gracia y Justicia, legajo 536.

${ }^{59}$ AGS, Gracia y Justicia, leg. 322. AHN, Consejos, leg. 14350, exp. 21.

${ }^{60}$ AGS, Gracia y Justicia, leg. 582.

${ }^{61}$ AHN, CON, leg. 15439, exp. 1.
} 
Descubierto el supuesto complot, el sistema punitivo del gobierno de Carlos III quedaba completamente claro. Tueros no fue propuesto por la Cámara de Castilla para piezas eclesiásticas hasta $1781 .^{62}$ Tres años después, otro voto le proponía en primer lugar para el obispado de Málaga. ${ }^{63}$ En 1787 era propuesto por un voto en segundo lugar para el obispado de Astorga. Y en enero de 1789, poco después de la muerte de Carlos III, la Cámara elevaría al rey una consulta en la que aparecía como primer candidato para el deanato de la catedral de Toledo. Fue rechazado por el rey. ${ }^{64}$ Tuvo que esperar, por lo tanto, hasta la muerte del rey y el declive de Floridablanca para ascender al episcopado, obteniendo en agosto de 1791 la mitra arzobispal de Burgos. ${ }^{65}$

Lo que ocurrió con Agustín Uriarte es más complejo. Me detendré en su análisis, ya que en su proceso afloran elementos que permiten caracterizar el alto clero que Carlos III quiso y, por el contrario, el que no quiso en sus dominios. Según exponía el Consejo extraordinario en la consulta citada, Uriarte mantenía correspondencia con los padres Bernardo Recio y Tomás de Larráin, procuradores de la Compañía de Jesús en Quito detenidos en Gerona, y con el criado de éstos, Tomás Pesantes, infringiendo en consecuencia la Real Pragmática de 2 de abril de 1767, que prohibía cualquier tipo de comunicación con los expulsos. Asimismo, mantenía correspondencia sobre una hipotética vuelta de los jesuitas, y sobre el rumbo que tomaba el gobierno de la monarquía, con el inquisidor en Corte (y ex compañero suyo en la Inquisición de Zaragoza) Pedro Fernández Arcaya, con su hermana María Francisca (religiosa dominica en Vitoria), y con una tal Teresa de Aguirre, residente en Azcoitia (Guipúzcoa). ${ }^{66}$

Lo interesante del caso viene dado en parte por la incautación de los materiales que sirvieron de prueba, lo cual permite ver el discurso que subyacía en su círculo relacional. En esta correspondencia es muy visible el malestar generado en algunos grupos tanto por la expulsión de los jesuitas, como por la dirección política del gobierno de Carlos III. Las críticas a éste y sus ministros iban enmarcadas en un discurso cuyos elementos, asociados a la expulsión de los jesuitas, se han estudiado

62 Ibídem

${ }^{63}$ AHN, Consejos, leg. 18991.

${ }^{64}$ AGS, Gracia y Justicia, leg. 328.

${ }_{65}$ AHN, Consejos, leg.. 15439, exp. 1. Para el caída del equipo de Floridablanca, Molas Ribalta, P. 2000: 106-107. Hernández Franco, J. 2008. La gestión política y el pensamiento reformista del Conde de Floridablanca: 552 ss. Murcia: Editum. [2 ${ }^{\mathrm{a}}$ ed.].

${ }^{66}$ AGS, Gracia y Justicia, leg. 582. 
recientemente por Eva Saint Clair e Inmaculada Fernández Arrillaga. ${ }^{67}$ Una de las cartas es digna de lectura por la condensación de elementos que contiene: duras críticas a los gobernantes de la monarquía (en particular a Campomanes), accidentes meteorológicos que provocan rayos que acaban en la cámara del rey de Nápoles, la predicción de la muerte de la futura reina de Nápoles, apertura de cuatro nuevas bocas del Vesubio, y defensa del nuncio apostólico de España y del projesuita obispo de Cuenca. Entre fenómenos sobrenaturales, profecías y revelaciones, se cuela un discurso de corte político. ${ }^{68}$

La rápida sucesión de los acontecimientos tras el descubrimiento de sus actividades confirma este subyacente carácter político. El día 14 de diciembre de 1767 Antonio Candano, administrador de correos en Vitoria, escribía a su primo Lázaro Fernández Angulo, consejero del Consejo de Hacienda, enviando una correspondencia incautada que consideraba "bando para una nueva sedición", y prometiendo nuevos materiales en el correo siguiente. ${ }^{69}$ El 17 de diciembre se celebraba una reunión del Consejo Extraordinario en la que se discutieron los materiales incautados. El día 21 del mismo mes el Consejo envió un oficio al Inquisidor General, quien acto seguido ordenaba a Agustín Uriarte que abandonara su plaza en la Inquisición de Zaragoza para marchar a residir su prebenda en Santillana. El día 24, el rey daba su aprobación al Consejo para que éste procediera como considerara más oportuno. ${ }^{70} \mathrm{En}$ cuestión de pocos días se había ventilado en la corte un proceso de máxima importancia que había comenzado en Vitoria. La maquinaria de supervisión, vigilancia y punición política, sustentada sobre redes de fidelidad al monarca, probaba ser de una elevada eficacia.

La hermenéutica del proceso realizada por los consejeros del Consejo Extraordinario y hombres cercanos al rey era claramente política. No importan tanto las profecías, sino las críticas al gobierno, ni el "fanatismo" de las revelaciones, en comparación con la saña contra los ministros del rey vertida en ellas. Cuando el día 22 de diciembre el conde

67 Saint Clair, E. 2003. "'Padre, los jesuitas vuelven". Revelaciones, profecías, y otros hechos maravillosos en Nueva España tras la expulsión de la Compañía de Jesús (1767-1772)". Revista de Historia Moderna. Anales de la Universidad de Alicante 21: 8-66. Fernández Arrillaga, I. 2002. "Profecías, coplas, creencias y devociones de los jesuitas expulsos durante su exilio en Italia", en E. Giménez López (dir.), Y en el tercero perecerán. Gloria, caída y exilio de los jesuitas españoles (1796-1803): 513-530. Alicante: Universidad de Alicante.

${ }^{68}$ AGS, Gracia y Justicia, leg. 582.

${ }^{69}$ AGS, Gracia y Justicia, leg. 311. Carta de Antonio Candano a Lázaro Fernández Angulo, Vitoria, 14 de diciembre de 1767.

${ }^{70}$ AGS, Gracia y Justicia, leg. 582. 
de Aranda enviara un oficio a Manuel Roda, en el que se incluía la correspondencia de Agustín Uriarte para que el rey la leyera, aprovechaba para destacar "la indisposición de dicho Inquisidor contra el sistema del día, y habrá comprobado que la providencia propuesta por el Consejo Extraordinario era necesaria, y fue blanda por carecer de lo que después se ha aumentado". No se podía aceptar, en adelante, la presencia de un clero no controlado, que fomentara "cláusulas supersticiosas e ilusas", "que en cualquiera otro reino, lo pusieran en un Patíbulo". El conde se sorprendía de que el hecho pudiera haber tenido lugar: "Y en éste ha estado depositada la Fe Cristiana y católica de una Provincia. ¿Qué buen ministro para concurrir a la fidelidad del rey, cuando para la multitud ignorante conviniese valerse de la verdadera religión?". ${ }^{71}$

Manuel Quintano Bonifaz, Inquisidor General, lo veía de un modo parecido. Según él, Agustín Uriarte había fomentado "fanáticas profecías y revelaciones", "con [...] espíritu de sedición ha infringido las Pragmáticas dirigidas a apagar los bullicios, y mantener en subordinación a los pueblos, con conocido desafecto del gobierno". En realidad, lo que según su condición de eclesiástico debería haber hecho sería "respetar por fieles vasallos las resoluciones del soberano, y providencias de su gobierno, la de esmerarse por el honor de tales en la más ciega [y] reverente sumisión por su parte e inspirarla, y fomentarla en otros". ${ }^{72}$

En todas las fases del proceso el rey quedaba aparentemente al margen, como figura atemporal, casi ajena a los sucesos. El rey no hace nada, pero todo se hace por el rey. Agustín Uriarte no se refería a él, en ninguno de sus escritos, en términos descalificativos. Muy al contrario, el rey ama la verdadera religión y a sus vasallos. Son sus ministros, en todo caso, los que le están pervirtiendo. Éstos, a su vez, tratan sobre el monarca refiriéndose a él en los mismos términos laudatorios, destacando su "innata clemencia", su disposición a entender y a cuidar de sus vasallos, y a perdonar las faltas cometidas. Él no tiene que ver con la política, pero toda política conduce a él.

Cuatro años pasa Agustín Uriarte en Santillana. Sufre allí La retirada de la gracia del rey, de la que en época de Fernando VI había disfrutado, y el apartamiento de los círculos de poder en los que se hallaba inserto. En 1771 elevaba al rey una petición de perdón, en la que se mostraba, según decía, muy arrepentido. Reunido, en consecuencia,

${ }^{71}$ AGS, Gracia y Justicia, leg. 311. Oficio del conde de Aranda a Manuel de Roda. Madrid, 22 de noviembre de 1767

${ }^{72}$ Ibídem. Carta de Manuel Quintano Bonifaz a Manuel Roda. Madrid, 21 de diciembre de 1767. 
el Consejo Extraordinario, se decidió, con la intervención favorable de Pedro Rodríguez Campomanes y el conde de Floridablanca, pedir al rey el indulto y su restitución al Santo Oficio. Los consejeros consideraban que ya había cumplido con su castigo, y que mostraba una sumisión absoluta al rey y a su gobierno. Pero el monarca no consideraba conveniente ni el indulto, ni la restitución. ${ }^{73}$

Sin embargo, el 16 de diciembre de 1771 aparecía como pretendiente al arcedianato de Acoba de la catedral de Lugo. En el memorial de petición, aseguraba haber sido indultado por el rey. ${ }^{74}$ Un mes más tarde, una carta de Manuel Roda le informaba de que, aunque el rey seguía teniendo en cuenta los motivos que le obligaron a separarle de la Inquisición de Zaragoza, movido de la "sumisión con que Vuestra Merced ha manifestado haber delinquido, no de voluntad, sino de entendimiento; y compadecido Su Majestad de la lastimosa situación, empeños y atrasos con que dice Vuestra Majestad se halla en la residencia" de la prebenda en Santillana, le confería la dignidad que había solicitado.

Agustín Uriarte quedaba así redimido por la gracia regia, que volvía a tocarle tras mostrar su arrepentimiento. La concesión de la dignidad comportaba, no obstante, algunas obligaciones para el futuro. Se hacía, en efecto, "esperando Su Majestad que Vuestra Merced se haga acreedor a esta gracia con su buena conducta, y proceder, verificando con las obras la lealtad, veneración y amor que dice Vuestra Merced profesa a la Persona de Su Majestad, siendo esto así muy propio y correspondiente al carácter, circunstancias y distinguido nacimiento de Vuestra Merced". ${ }^{75}$

No tardaría el agraciado en hacerse el mayor valedor de esta exigencia de futuro. Estaba disciplinado. Estaba donde los ministros y el rey querían. Su vida anterior habría sido un cúmulo de errores, en la que no había sabido ver la grandeza del monarca y su gobierno. Se mostraba dispuesto a subsanar esos errores sirviendo al rey, y a la religión. Satisfecho por recuperar la gracia regia, decía estar también penetrado

"del más vivo dolor al considerar, con lo que Vuestra Excelencia me expresa, que he sido tan infeliz, que he incurrido, aunque ignorantemente, en la desgracia del mejor de los reyes, pues habiendo experimentado sus benévolos influjos, he tenido la

${ }^{73}$ Ibídem. Consulta del Consejo Extraordinario de 29 de mayo de 1771

${ }^{74}$ AGS, Gracia y Justicia, leg. 366.

${ }^{75}$ AGS, Gracia y Justicia, leg. 311. Carta de Manuel Roda a José Agustín Uriarte. El Pardo, 27 de enero de 1772. 
honra de besar repetidamente su Real Mano cuando pasó por Zaragoza, no tenía motivo sino para sacrificarme por su servicio, como me lo han inspirado siempre mi nacimiento, crianza y empleos, en los que he procurado acreditarlo, cuanto mi cortedad ha alcanzado, como pueden informar los que han sido mis jefes, no teniendo otro norte en mi proceder que el mejor servicio de ambas majestades; en cuyo verdadero concepto puede usted creer, cuánto me será más sensible la pérdida del honor en tan delicado punto, que todas las demás temporales y de intereses que me hayan acaecido, por lo que lleno de confusión y de rubor suplico a Vuestra Excelencia me ponga a los pies de Su majestad como el vasallo más obligado, y reconocido ante sus bondades, y como el más amante de la Real Persona, fiel y rendido a su voluntad, exponiendo al mismo tiempo mi más rendida gratitud por las gracias que me acaba de hacer, la que me deja nuevamente obligado a rogar a dios... como lo hago diariamente, prolongue los preciosos días de Su Majestad cuanto importa al bien universal de esta Monarquía, y en lo demás quedo enterado de cuanto Vuestra Excelencia me previene de su Real Orden para ejecutarlo con la puntualidad que debo, y con este motivo, me ofrezco a la obediencia de Vuestra Excelencia con el mayor respeto, para emplearme en su obsequio, ínterin ruego a nuestro Señor guarde a Vuestra Excelencia los muchos años que deseo"76

La sumisión es absoluta. El agradecimiento a Manuel Roda por su mediación en la renovación de la gracia se convierte, en carta enviada tres días después, en nueva ocasión para mostrarla. Reconocía lo mucho que el Secretario de Gracia y Justicia había contribuido a la obtención para él de la dignidad en la catedral de Lugo, debida, en última instancia, "a la gran piedad de Su Majestad".

Resumiendo, un disidente quedaba reducido a la docilidad, un descontento a la obligación, a través del premio y el castigo, que se erigen en los dos grandes mecanismos de poder que articulan la gracia. Punición, disciplinamiento y redención por la gracia real formaban, por lo tanto, la cadena de subordinación y adoctrinamiento que el rey y sus ministros implementaban para conseguir la sujeción del alto clero disidente en este periodo.

\section{CONCLUSIÓN}

${ }^{76}$ Ibídem. Carta de José Agustín Uriarte a Manuel Roda. Santillana, 1 de febrero de 1772 
El avance y modernización de los Estados en la Europa del siglo XVIII vio uno de los polos que dificultaban su desarrollo en el clero, súbdito de dos potestades que se pretendían soberanas. En este contexto, la firma de Concordatos con la Santa Sede proliferó por todo el espacio europeo, como nueva forma de relación entre ambos entes. La esfera política conseguía por este medio un control directo sobre unas estructuras que anteriormente escapaban a su dominio.

Carlos III llegaba al trono español con la gran obra concordataria concluida. Su confesor y ministros serían los que actuaran en un doble sentido para la defensa de sus derechos. Por un lado, incrementando las precauciones hacia las posibles injerencias de la Santa Sede. Por el otro, vigilando constantemente la aparición de cuadros clericales más inclinados hacia la Ciudad Eterna que hacia el Palacio Real.

Como se intentado exponer, la integración política del clero en la monarquía queda, durante este periodo, embebida en la concesión o negación de la gracia real. La cuestión tiene su importancia.

La concentración de todo este poder en la persona del monarca, que establece una relación de patronazgo con su clero, no produjo mayores problemas mientras el sistema mantuvo su estabilidad. Sin embargo, el cataclismo estaba a punto de llegar. Cuando el sistema se saturó a finales del siglo, la cohorte clientelar de los clérigos que no pudieran ser premiados se establecería en los márgenes del sistema, buscando nuevas vías de ascenso y nuevos patronos. A partir de 1808, la gracia real iba a perder definitivamente su capacidad de integración y, en adelante, las categorías pluriseculares de sacerdocio e Imperio iniciarían un proceso de escisión que llega a nuestros días.

\section{BIBLIOGRAFÍA CITADA}

Alcaraz Gómez, J. F. 1995. Jesuitas y reformismo. El Padre Francisco de Rávago (1747-1755). Valencia: Facultad de Teología.

Andrés-Gallego, J. 2003: El motín de Esquilache, América y Europa: 491-528. Madrid: Fundación Mapfre Tavera/Consejo Superior de Investigaciones Científicas.

Arribas Arranz, F. 1963. Relaciones y justificantes de méritos y servicios de catedráticos, profesores y opositores a cátedras, Universidad de Valladolid. Valladolid. 
Barrio Gozalo, M. 2001. "El sistema beneficial en la España del siglo XVIII. Cambios y pervivencias". Cuadernos dieciochistas 2: 73-107.

Bérenger, J. 2007. Joseph II d'Autriche. Serviteur de l'État. Paris: Fayard.

Bergin, J. 2004. Crown, Church and Episcopate under Louis XIV. Yale: Yale University Press.

Blet, P. 1981. "Fidèle au pape, fidèle au roi", en Y. Durand (coord.), Clientèles et fidélités à l'époque moderne. Hommage à Roland Mousnier: 315-332. Paris: PUF.

Carabias Torres, A. 1991. "Catálogo de colegiales del Colegio mayor de San Bartolomé (1700-1840)". Studia Histórica. Historia Moderna IX: 43-88.

Carrasco Rodríguez, A. 1996. "El Patronato Real en Cataluña, 1715 - 1775". Revista de Historia Moderna 13-14: 95-122.

Carrasco Rodríguez, A. 1997. El Real Patronato en la Corona de Aragón. El caso catalán, 1715 - 1788. Alicante: Universidad de Alicante.

Carreras Panchón, A. Granjel, M. 2005. "Regalismo y policía sanitaria. El episcopado y la creación de cementerios en el reinado de Carlos III". Hispania Sacra 116: 589-624.

Cortés Peña, A. L./López Muñoz, M. A. 1996. "Las visitas "ad limina" y las visitas pastorales como instrumento de control (la diócesis de Granada en la segunda mitad del siglo XVIII)", en J. L. Castellano, (ed.): Sociedad, administración y poder en la España del Antiguo Régimen: 288-289. Granada: Universidad de Granada/Diputación Provincial de Granada.

Dedieu, J. P. 2005. "Pour une approche relationnelle de l'épiscopat: I'Espagne du XVIIle siècle", en Sous le sceau des Réformes / Au contact des Lumières, Hommage à Philippe Loupés: II, 19-30.. Burdeos: Presses universitaires de Bourdeaux.

Dedieu, J. P. 2005. "La muerte del letrado", en F. J. Aranda Pérez (coord.), Letrados, juristas y burócratas en la España Moderna: 479-512. Cuenca: Universidad de Castilla La Mancha.

Egido, T./Pinedo, I.1994: Las causas "gravísimas" y secretas de la expulsión de los jesuitas por Carlos III. Madrid: Fundación Universitaria Española

Egido, T. 1989. "Actitudes regalistas de los obispos de Carlos III", en C. $M^{a}$. Cremades Griñán (ed.), Estado y fiscalidad en el Antiguo Régimen: 67-83. Murcia. 
Egido, T. 2002. Opinión pública y oposición al poder en la España del siglo XVIII (1713-1759): 195-235. Valladolid: Universidad de Valladolid-Fundación Española de Historia Moderna.

Enríquez Agrazar, L. 2006. De colonial a nacional: la carrera eclesiástica del clero secular chileno entre 1650 y 1810. México D.F.: Instituto Panamericano de Geografía e Historia.

Fernández Arrillaga, I. 2002. "Profecías, coplas, creencias y devociones de los jesuitas expulsos durante su exilio en Italia", en E. Giménez López (dir.), Y en el tercero perecerán. Gloria, caída y exilio de los jesuitas españoles (1796 - 1803): 513-530. Alicante: Universidad de Alicante.

Giménez, E./ Martínez Gomis,M. 1992. "El episcopado español y la encuesta del Marqués de Ensenada de 1750", en E. La Parra/J. Pradells (eds.), Iglesia, Sociedad y Estado en España, Francia e Italia: 263-299. Alicante.

Gómez Rivero, R. 1999. El Ministerio de Justicia en España (17141812). Madrid: Centro de Estudios Políticos y Constitucionales.

Gómez Urdáñez, J. L. 2001. Fernando VI. Madrid: Arlanza.

González Fuertes, M. A. 2003. La organización institucional de la Cámara de Castilla en la época borbónica. Córdoba: Servicio de Publicaciones de la Universidad.

Gutiérrez Torrecilla, L. M. 1992. Catálogo biográfico de los colegiales y capellanes del colegio mayor de San Ildefonso de la Universidad de Alcalá (1508-1786). Alcalá de Henares.

Hermann, Ch. 1988. L'Église d'Espagne sous le patronage royal. Essai d'ecclésiologie politique. Madrid: Casa de Velázquez.

Hespanha, A. M. 1993. La gracia del derecho: economía de la cultura en la edad moderna. Madrid: Centro de Estudios Constitucionales.

Irigoyen López, A. 2008. "Un obispado para la familia: Francisco Verdín Molina, prelado de Guadalajara y Valladolid en la segunda mitad del siglo XVII". Historia Mexicana LVIII/2: 557-593.

Irles Vicente, M․ C. 1996. "Tomismo y Jesuitismo en los Tribunales españoles en Vísperas de la expulsión de la Compañía". Revista de Historia Moderna 15: 73-99.

Jiménez Sureda, M. 1999. L’Església catalana sota la Monarquía dels Borbons. La catedral de Girona en el segle XVIII. Barcelona.

León Navarro, V. 1999. "Rafael Lasala y Locela, obispo auxiliar de Valencia. Su postura ante la extinción de los jesuitas". Revista de historia moderna. Anales de la Universidad de Alicante 17:353-372 
Loupés, Ph. 2000. "Los mecanismos de la Cámara de Castilla en el siglo XVIII. La selección del alto personal judicial”, en J. L. Castellano/J. P. Dedieu/Ma V. López Cordón (eds.), La pluma, la mitra y la espada. Estudios de Historia Institucional en la Edad Moderna. Madrid: Universidad Burdeos/Marcial Pons.

Martínez Peñas, L. 2007. El confesor del rey en el Antiguo Régimen: 764. Segovia/Madrid: Colegio Universitario Santo Domingo de Segovia-Editorial Complutense.

Mestre Sanchís, A. 2002. "Nueva dinastía e Iglesia nacional", en P. Fernández Albaladejo (ed.), Dinastía y memoria de España en el siglo XVIII: 548-567. Madrid: Marcial Pons / Casa de Velázquez.

Millet, H./Moraw, P. 1996. "Clerics in the State", en, W. Reinhard (ed.), Power elites and the State building. The origins of the modern state in Europe, $13^{\text {th }}-18^{\text {th }}$ centuries: 174-188. New York: Clarendon Press.

Molas Ribalta, P. 2000. Los magistrados de la llustración. Madrid: Centro de Estudios Políticos y Constitucionales.

Molas Ribalta, P. 1996. "La estructura del Estado y las elites de poder", en A. Guimerá (ed.), El reformismo borbónico. Una visión interdisciplinar: 61-73. Madrid: Alianza.

Olaechea, R. 1981. "Política eclesiástica del gobierno de Fernando VI", en VV.AA, La época de Fernando VI: 139-224 Oviedo.

Olaechea, R. 1983. "Política anticolegialista del gobierno de Carlos III". II Simposio sobre el Padre Feijoo y su siglo: 207-246. Oviedo.

Olaechea, R. 1965. Las relaciones hispanorromanas en la segunda mitad del siglo XVIII. La agencia de preces. Zaragoza.

Paquette, Gabriel G. 2008. Enlightenment, Reform and Governance in Spain and its Empire, 1759-1808): 56-92. Basingtoke/Nueva York: Palgrave Macmillan.

Pujol Aguado, J. A. 1995. "El clero secular al servicio del Estado. Intento estatal de control de la Iglesia durante la Guerra de Sucesión". Revista de Historia Moderna, 13-14: 73-93.

Rivera García, A. 1999. La política del cielo. Clericalismo jesuita y estado moderno. Hildesheim: Georg Olms.

Saint Clair, E. 2003. "'Padre, los jesuitas vuelven". Revelaciones, profecías, y otros hechos maravillosos en Nueva España tras la expulsión de la Compañía de Jesús (1767-1772)". Revista de Historia Moderna. Anales de la Universidad de Alicante 21: 8-66. 
Sierra Nava, L. 1984. "Una década de política religiosa de Carlos III vista por los ojos de un nuncio y un abate romanos (1776-1785)", en Cuadernos de investigación histórica 8: 171-202.

Uriarte Astarloa, J. M ${ }^{\mathrm{a}}$. 2002. Pablo Pedro Astarloa: biografía. Durango: Museo de Historia.

Vergara, A. 1985. Sáenz de Buruaga. Un linaje histórico en Cigoitia: 12-33. Vitoria: Caja Provincial de Álava-Arabako Kutxa.

Pastor, L. Von. 1937. Historia de los Papas desde fines de la Edad Media. Versión de la cuarta edición alemana por el Padre Manuel Almarcha (S.I). Vol. 36: Historia de los Papas en la época de la Monarquía Absoluta: 362-478. Barcelona: Gustavo Gili.

Zuluaga Cítores, Á. 1999. Sebastián De La Quadra Primer Marqués De Villarías (1687-1766) Secretario De Estado En El Reinado De Felipe V, Muskiz: Ayuntamiento de Muskiz/Petronor. 